\title{
Performance Management in State Universities in Cameroon: An Administrator's Perspective
}

\author{
Agbor Michael Ntui: Faculty of Education the University of Bamenda, Cameroon.
}

\begin{abstract}
This study provides an in-depth understanding of how administrators perceive the purpose and value of the performance management systems in state Universities of Cameroon; how the administrator assess the effectiveness of current performance management processes in the department; the different dimensions of how administrators perceive the impact of academic managers on their work performance; the extent to which administrators respond to the process, measure and outcomes involved in operating the performance management system. The study also analyzes what administrators think is an effective performance management system in the state Universities. The research adopted a qualitative case study approach by selecting 12 administrators from 6 state Universities with varied backgrounds in terms of years of service, seniority and gender. Data were collected through in-depth, semi-structured interviews and documentary sources. Among the major findings were that the participants found the meaning and purposes of performance management ambiguous; and that the many different processes contained within the system were perceived as fragmenting and confusing in achieving the intended outcomes. Compounding the concern was the lack of dedicated and able academics to manage the process.
\end{abstract}

Key words: Performance management, Perspective, Administrator, State University.

\section{Introduction and the Problem}

Organization and institutions, academic and non-academic are established or called upon to perform specific duties or render particular services. These duties and services must be clearly specified. Management of performance should be an on-going process that involves both the employer and employee in:

a) Identifying and desorbing realistic and appropriate means of attaining the institutional goals and standards.

b) Identifying, describing and updating the job description and job functions.

c) Giving and receiving information relative to employer performance.

d) Constantly examining goals of the institution and relating these goals to the objectives

e) Appraising the level of performance of the employee.

f) Planning on training programs that will lead to sustaining, improving performance standards and

g) Relating performance appraisal to rewards.

Performance management can be regarded as a systematic process by which the overall performance of an organization can be improving the performance of individuals within a team framework. It is a means for promoting superior performance by communicating expectations, defining roles within a required competence framework and establishing achievable benchmarks. According to Armstrong and Baron (2004), Performance Management is both a strategic and an integrated approach to delivering successful results in organizations by improving the performance and developing the capacities of teams and individuals. Some define performance 
management as a specific set of practices implemented by managers to control the behavior of individuals, with the ultimate aim to improve organizational performance (Elton 2004).

An administrator is one who directs the activities of other persons and undertakes the responsibility for certain objectives through these efforts while leadership refers to people who bend the motivations and actions of other to achieving certain goals; it implies taking initiate (Middlehurst 2004).

Economic and political changes over the past few decades have had a profound impact on the traditional relationship between the government and universities, their management and academic in the Cameroon state Universities. Higher education systems are increasingly seen by governments as an instrument to enhance national competitiveness in the global market (Slaughter and Leslie 1997). This has resulted in a skilled and educated workforce (Jary and Parker 1998). This market orientation has led to the emergence of a new public sector.

Emphasis in organizational management has changed from command-and-control model towards the facilitation model of leadership. This change has necessitated the evolution of the concept of performance management as a new concept in the Human Resource Management Model (Armstrong and Baron 2004) and in doing so it has emphasized the need to consider it as a management problem.

This model assumes that the employee and the employer must have goals and objectives, which are coincident with the main missions of the organization or institution. If the organization is broken into units or departments, the goals and objectives of the employees in each department must support the objectives in that department, which in turn support the overall objectives of the organization. We consider the University system as an example. The university normally has the three missions of teaching (and learning), research and community service. These missions are translated to teaching programs in different departments, research units and the provision of skilled labour to the general public. These departments and units support the main missions of the University by carrying out their individual tasks to support the goals of the University.

The performance management process in the University for example should provide an opportunity for the University and employees to discuss unit or departmental goals and jointly create plans for achieving those goals. This is usually done through regular meetings and informal discussion in which old teaching programs are revised and updated, new ones are proposed and unproductive ones deleted. These meeting and discussions should foster only the achievement of institutional and organisational goals but also should contribute to the professional growth of the teachers and the employees at large.

The arrival of Information Technology (IT) has changed the work environment from a manual to a mechanized one. This changing environment offers many new challenges and opportunities and needs to be sustained. Unexpected demographic growth, increased enrolment pressures in academic institutions, competition for teaching places, pressures to reduce administrative costs, regulatory and policy pressures, increased services expectations, and greater influence of customers and various stakeholders all influenced the way that we do our work today. There are more accountability demands and new organisational model emphasizes a focus on decision-making and accountability at the level where the work is done, and the development of a service culture that rewards team performance, and integration of actives.

Given that performance management is a manifestation of Managerialism (Middlehurst and Kennie 2003), the extent to which the ideology of Managerialism has permitted Universities could explain the growing interest in performance management in higher education sector.

Deem and Brehony (2005) define new Managerialism as an ideology that refers to ideas, values and practices imported from the business sectors for managing public institutions in pursuance of efficiency, excellence and continuous improvement. The characteristics of imported management techniques and practices include monitoring employee performance, imposing tighter financial management control to attain targets, efficient use of resources for improved productivity, quantitative measures performance, benchmarking and performance management (Randle and Brady 1997; Deem and Brehony 2005).

The emergence of Managerialism in Universities can be traced back to the public sector reform which took place in the early 1980s. One of the consequences of this reform was the shift in managerial thought on how to manage public organisations to "new public management" or "new Managerialism" (Pollitt 1993; Ferlie, Ashburner et al. 1996);. With the belief that the new managerial approach "will deliver the ,three Es" of economy, efficiency, and effectiveness in public services and therefore can ensure value for taxpayers" money and eliminate waste" (Randle and Brady 1997), successive governments have been

Vol. 1, No. 2, pp. 132-140

DOt: $10.53935 / 2641-533 x . v 1 i 2.81$

Article History:

Received: 18 June 2018

Revised: 2 October 2018

Accepted: 23 November 2018

Published: 21 December 2018

(C) 2018 by the authors; licensee Academic

Publishing Group

133 pushing all public organizations including Universities to adopt this new set of managerial principles. 
The movement towards Managerialism in Universities was encouraged as early as 1985 in the UK by the Jarratt (1985). It urges that Universities should be considered as corporate organization and their Vice Chancellor should be seen as Chief Executives in the governance of Universities (Dearlove 1998). In addition, the external pressure to improve quality and increase productivity has motivated Universities to increasingly adopt corporate practices and techniques associated with new Managerialism (Deem 1998; Cohen, Duberley et al. 1999).

Applying the managerial practices to higher education is seen as a new departure because "it entails interrelated organizational, managerial and cultural changes leading to a tightly integrated regime of managerial discipline and control, which is radically different from the traditional collegial model experienced by academics" (Deem 2001). To what extent has the ideology of managerialism entered into the academic world?

In a study of six British Universities, which involved 105 semi-structured interviews with academics and administrators, Henkel (1997) found that five Universities had moved towards a more managerial structure by establishing a strong management team to run the operations and creating non-academic support units to mediate the government"s performance expectations and policies. Alongside the growth in administrative functions, the number of Human Resources professionals has increased substantially in Universities to provide support in managing academics (Wilson 1991; Jackson 2001)

Linking results of Research Assessment Exercise (RAE) to the size of the funding allocation is seen as central to the growth of managerialism (Harley and Lee 1997; McNay 1999). In a study on the impact of RAE conducted by McNay (1999) which involved 30 institutional cases, it reveals that RAE has caused some Universities to change their recruitment strategies with a specific focus on hiring "research active" academics and centralize research management with more emphasis on efficiency and control. Another emerging change identified by this study is that some universities have clustered research staff from various departments together by creating research centers to free them from teaching responsibilities (McNay 1999). The gradual separation of teaching from research increases job specification reinforcing the managerial ideology for efficiency.

Apart from organizational changes, the appointments of academic managers have become pervasive with mandates to co-ordinate, integrate, control and regulate the work of academics (Randle and Brady 1997; Deem 1998). According to Deem (2001), this managerial role has been performed either by academics on a part-time basis or full-time professional administrators. While this is still new to some Universities and most appointed managers do not have private sector experience (Deem 2001; Deem 2004), they seem to have embraced the concept of managerialism. In a study of four Universities in the UK, (Prichard and Hugh 1997) find a clear presence of managerialism from the standpoint of senior post holders. This finding is affirmed by a subsequent study conducted by Deem (2001) to examine the extent to which the idea about new manaferialism had permitted into higher education between 1998 and 2000. The results reveal that most surveyed academic managers, despite having a background as academics themselves, have a strong belief in their right to manage other academics. The legitimacy of academic managers seems to be further bolstered due to the need to satisfy the requirements set by the external quality audit and assessment on research and teaching (Deem and Brehony 2005)

With the emergence of the academic manager to take on management roles along with the need to raise the performance standards on research and teaching, the concept of performance management is increasingly seen as an integral part of organizational life in universities to define, measure, and stimulate employee performance (Jackson 2001).

The inclusion of performance management into the domain of academic appears to be challenging. Performance management has been perceived as a management tool imported from the private sector and other parts of public sector seeking to introduce command and control on work behavior in order to achieve institutional objectives. This administrative principle is in conflict with university traditions of "collegiality" and ,academic freedom" therefore, the obligation of such a system may be seen as challenging the traditional ways of how academics self-regulate their work and their long-established professional identities. Unfortunately, there is an apparent inconsistency in the literature on the impacts of performance management on academic. Using different perspectives to view the impacts of performance management could reach opposite conclusions on the matter. This paradox calls for a study to seek a more in-depth understanding of

Vol. 1, No. 2, pp. 132-140

.53935/2641-533x.v1i2.81

Funding: This study received no specific

Article History:

Received: 18 June 2018

Revised: 2 October 2018

Accepted: 23 November 2018

Published: 21 December 2018

(C) 2018 by the authors; licensee Academic

Publishing Group

134 how and whether academics adjust and respond to the changes brought by performance management. 


\section{Objectives of the Study}

This piece of work intends to investigate the following:

1. To examine how administrators perceive the purpose and value of the performance management systems in the state Universities of Cameroon.

2. To find out how the administrator assess the effectiveness of current performance management processes in the department.

3. To explore the different dimensions of how administrators perceive the impact of academic managers on their work performance in state Universities.

4. To investigate the extent to which administrators respond to the process, measure and outcomes involved in operating the performance management system in state Universities.

5. To analyze what administrators think is an effective performance management system in the state Universities.

\section{Research Questions}

1. How do administrators perceive the purpose and values of the performance management systems in the state Universities?

2. How does the administrator assess the effectiveness of current performance management processes in the department?

3. In what dimensions do administrators perceive the impact of academic managers on their work performance?

4. To what extent do administrators respond to the process, measures and outcomes involved in operating the performance management system?

5. What do administrators think is an effective performance management system in the state Universities?

\section{Methodology}

The paper is based on extant literature on strategic talent management and University performance. The literature was analyzed and synthesized from the concepts clarification to the relationship, and results were used to formulate a research framework. A semi-structured interviewing approach was used to elicit the required information together with documentary analysis to confirm and supplement the findings. The data collected for analysis were coded and then organized under the key research question headings. Patterns and trends drawn from the interview questions have gathered together to respond to the key research questions.

\section{Findings and Discussions}

\subsection{How do Academic Participants Perceive the Purposes and Values of the Performance Management System?}

The extent to which University management and academics share the same view or have a common understanding of the term ,performance management" is of strategic importance to the implementation of the program. Any gap or mismatch could result in skepticism among academics about the intention of introducing performance management. At the Universities, the performance management system is designed to serve multi-level purposes to accommodate the need to fulfill the external accountability requirements, the need to meet the University"s mission as an organization, and the need of individual academics for professional development. To meet these multi-level purposes, the Universities operates five processes under the umbrella of the performance management system that include a development-oriented appraisal scheme, a research monitoring process, mentoring and probation reports for newly-joined academics, teaching evaluation in the form of peer observation and student feedback surveys, and reward programs such as a promotion and an achievement bonus scheme to recognize outstanding performance (for example, President Biya"s grant to University students)

While this system appears to have many good characteristics, at least in principle, to support the International Journal of Educational Studies Vol. 1, No. 2, pp. 132-140 University"s needs to meet the accountability requirements and the individual needs for professional development, the term

„performance c ambiguous. As revealed from the findings, thirty-three out of 60 participants included in this study have explicitly claimed that the term is either confusing or non-existent in the University. In addition, almost all of the academics interviewed were not well-versed in the reasons for the University 
introducing performance management. Twelve participants speculated that the purpose of performance management was for managerial control, based on what they had read from the literature.

This speculative view was also supported by the other senior academics, but their judgment was based on their personal belief on what the system should do rather than their understanding of the University"s policy. Confusion is also found among the remaining administrators. Their perception of performance management was largely influenced by their experience with the appraisal scheme leading them to believe that the purpose of performance management is primarily for individual professional development.

The confusion is due to the fact that previous literature argues that the term ,performance management" is exclusive, due to its open approach, which tends to serve multiple purposes (Williams 2002) and involves a range of varied activities that are not necessarily coherent with each other (Den Hartog, Boselie et al. 2004; Brown 2005). For this reason, the literatures has not yet to come up with a universal definition, resulting in a wide range of different interpretations depending on individuals beliefs or values.

The above discussion signals the importance of ensuring the multiple processes of the system are wellintegrated as a package of measures, and that policy value of each process is clearly distinguished and articulated. However, the findings of this study confirm that this co-ordination is lacking in the three State Universities. At least three senior administrators openly criticized the system as fragmented with no coordination between processes.

Furthermore, two other administrators questioned the link between the performance and reward programs. The lack of co-ordination seems to add confusion among academics about what the real purpose of performance management is, the result of which leads them to interpret it in their own way, based on their personal values. Guided by entrenched academic identity (Harley and Lee 1997) regarding personal values and the experience of traditional values of an appraisal scheme, it is evident that the small group of academic participants in the case school still believes that performance management is primarily for professional development. This result challenges the conventional view that performance management is a manifestation of managerialism focusing on increased efficiency, effectiveness, and accountability (Middlehurst and Kennie 2003).

Taken together, it is plausible to argue that it is the confusion and uncertainty about the meaning of the term performance management and the purpose of implementing multiple programs that contribute to the gap between the University"s intention and the view of the participants. The lack of concordance raises a concern about whether academics will accept and commit to the performance management system.

\subsection{How do Academic Participants View the Effectiveness of Current Performance Management Processes in the Department?}

According to conventional Goal-Setting Theory and Expectancy Theory, performance management systems can raise motivation if three requirements are met: work objectives and appropriate work priorities are clarified and specified; assessments are fair and accurate; and a clear connection between financial incentives and academics" efforts is established. This study, however, reveals that the systems implemented by the 6 state Universities have been effective in meeting these three requirements;

Goal setting: considerable concern is raised in the literature about setting clear goals in the higher education sector (Clark 1983). Thirty participants asserted that the mandate of the school is so broad and ambiguous that it is almost impossible to determine specific and achievable goals, a finding consistent with Clark"s study.

Indeed, almost all participants included in the study indicated that they had received very little information about the organizational goals from appraisers at the goal-setting meetings. Arguably, the goalsetting exercise at the Cameroon Universities (cases studied) could be perceived as a self-identification process as pointed out by one senior lecturer. This arrangement, however, did not seem to create problems for the professors. Based on responses, from fifteen participants, their professional identity and enthusiasm enabled them to know what they individually needed to achieve. What seems to be of concern, however, for more than half of those interviewed is the intensification of academic work fuelled by administrative work for accountability purposes; the reduction of clerical and secretarial support in helping them achieve administrative goals; and their involvement in „entrepreneurial" activities. This „overwhelming" workload could potentially force most of the participant academics to "muddle through" the various activities

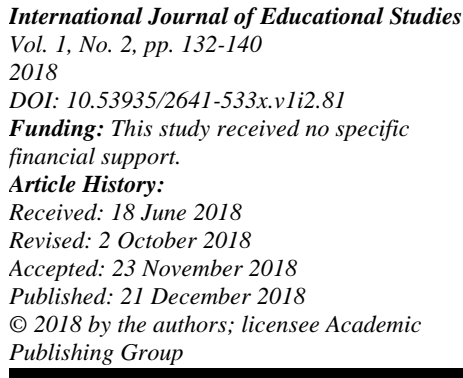


imposed on them, rather than rely on a more organized work schedule to determine their goals and work priorities.

Performance measures: unsurprisingly, seeking valid and reliable measures to accurately determine the performance level of teachers in research, teaching, and administration has proved to be a challenge. All participants in the study, including the newly hired lecturers, agreed that research performance is measurable based on a number of quality publications and experience.

Consistent with Talib (2003) research, the tone set by the Research Assessment Exercise requirements seems to have been accepted by academics as key measures for their research performance. Only twelve participants voiced Elton (2004) concern as a caution that the use of simple productivity measures to judge their research performance could encourage changes in short-term behavior resulting in unintended and detrimental consequences such as eschewing research that takes a longer time to complete.

Two of the Universities have put in place a peer-observation and a student feedback scheme to measure the quality of teaching, about half of the participants concurred with the conventional view that the lack of valid measures to evaluate teaching effectiveness was still a concern. At least two participants argued that the observation of classroom practice could only produce a snapshot result and its validity was subject to the honesty and the ability of the observer, a finding consistent with Wragg, Haynes et al. (2004)

In addition, this study underscores the difficulty in using student achievement to judge teaching performance. Despite all participants being proud of their teaching skills, forty participants voiced a concern about establishing causal links between teacher contributions and student performance, due to many uncontrollable factors.

Administration was viewed by most participants as a chore and was characterized as the „least satisfying task". Identifying appropriate measures to quantify the performance in administration seemed to be a challenge according to the findings. With the intensification of administrative work and the fact that academics generally claim they do not gain intrinsic satisfaction from the administrative work itself (Barnes 2000; Byron 2005), the consequence of not having appropriate performance indicators to recognize the contribution to this dimension of work could greatly undermine the commitment of academics to the organization, according to the perspective of Psychological Contract Theory in Stiles, Gratton et al. (1997). In addition, administration is one of the criteria for promotion and bonus awards. The absence of performance indicators to quantify achievements in this area may put those academics whose involvement in administration overwhelms teaching and research at a disadvantage for promotion and receiving rewards.

Financial incentives: consistent with the existing knowled (Varlaam, Nuttal et al. 1992; Lacy and Sheehan 1997), this research confirms that academics tend to be more responsive to intrinsic rewards such as professional competency and autonomy than financial incentives, a fact that further undermines the perceived effectiveness of the current performance management processes. Thirty participants criticized the tenuous link between performance and reward in the State Universities, and one of them further argued that the reward system could create a divisive and counterproductive environment Kohn (1993). Another three participants described their reward experiences, but felt that the reward progrmme could only bring limited impact. While the academics were not in favour of financial incentives, it appears that reward programs are generally viewed as hygiene factors and must be maintained to avoid dissatisfaction is the lack of clear or proactive communication to make the programs more transparent to all participants to ensure they understand the steps needed in order to increase their opportunities to quality for the rewards.

A further concern is linked to the professors" belief as to whether they have the ability and opportunity to engage in activities that qualify for the rewards. Being a research-led University, the key determinant factor rewards, particularly for promotion, is research performance. Prewitt, Phillips et al. (1991) and Grant (1998) contend that this bias towards research and against teaching puts those academics whose role is primarily teaching at a disadvantage. In this study, the research emphasis in itself, however, does not seem to be a source of disagreement for many of the academics as they are well aware that they work in a research-led University. It was a particular concern, however, for the teacher-training staff who could claim little opportunity to engage in research, as opined by five participants. Another emerging concern is that most lecturers are burdened with heavy teaching and administration loads that impair their ability to complete the targeted research work and thus undermine their chance to receive the expected rewards.

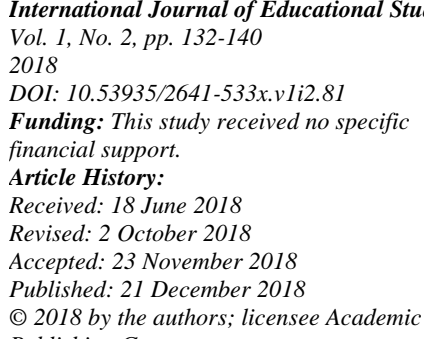




\subsection{How do Academic Participants Perceive the Impact of the Academic Manager on their Work Performance?}

The successful implementation of performance management requires the manager to be properly equipped for the role and to have necessary resources and time to discharge the performance management responsibilities. This study underscores the dilemma in relation to appointing the appropriate personnel to manage this process.

The research identified four key stakeholders involved in the performance management processes in the 6 state Universities. Half of the participants felt that the Head of Departments (HOD) was their line manager and should therefore have a vital role in performance management. However, it was generally agreed that the otherwise flat structure, with a wide span of control, made it almost impossible to have the HOD carry out the performance management activities for more than 40 lecturers in the University. Indeed, the role of the HOD in the University is limited to overseeing the processes to ensure they adhere to the University"s policy and guidelines. The actual performance management responsibilities have devolved into three different roles of administrators (course leader, academic research director, and appraiser) who take on this role in addition to their academic work. While the involvement of three different people can address the needs of each separate process, that is accountability versus development, lecturers may become confused with the feedback they receive from each stakeholder. Such feedback and advice could be varied and conflicting. A further significant concern raised by $40 \%$ of the participants centered on who should have the ultimate responsibility to monitor the performance of all facets of academic work. Given that each academic leader is only responsible for one aspect of academic work, it raises a question of who is the central person with the accountability for collating all performance information together from various processes and deciding on an overall rating for each academic.

The above findings demonstrate two overarching problems: role ambiguity and role effectiveness faced by administrators when carrying out the performance management activities in addition to their regular academic work.

\subsection{How do Academic Participants Respond to the Process, Measure, and Outcomes Involved in Operating the Performance Management System?}

Three different response strategies were identified among the participants in this study: a "sailing" strategy, a,redefining" strategy, and a „struggling" strategy, as explained below;

Nineteen administrators interviewed felt that the current performance management arrangements have minimal impacts on their working lives and thus they have made no change to their working practices. The entrenched collegial culture in the University and the personal pride in their self-efficiency seem to lead them to believe they can continue their usual practices (,sailing" strategy) to contribute their best to the job, regardless of measures and processes imposed on them under the umbrella of performance management. Another factor contributing to this belief is linked to their relative experience with performance management. Two newly-hired lecturers in this group indicated that they had been subject to a more rigorous performance management system in their previous employment, for example, in secondary or primary schools, and therefore had less trouble adapting to the system place.

Three participants used a lens through which they saw the positive aspects of the system and the scope of the academic work that would provide them with enough room to configure their job focus (redefining strategy) to regain any loss of professional identity due to the control aspects the system.

Based on the above findings, it is plausible to argue that there is little evidence to support the conventional view (Simmons 2002) that the performance management system in the Universities has undermined academic freedom.

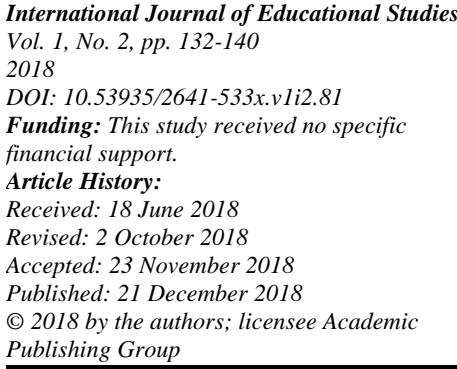

\subsection{What do Academic Participants Think is an Effective Performance Management System?}

Need for a more structured system: The suggestions offered by participants to improve the system are quite specific and focused on those issues identified above. What is strikingly identified by this research is that, instead of finding that academics argue for the elimination of the performance management system in defending their professional autonomy, it is evident that some participants included in the study call for more structured and integrated system. To address the concern about the fragmentation of the current process, at least thirteen senior administrators argued for a more structured system to integrate the various components of 
performance management by using appraisal as a central tool to pull all information together and have a more structured management team with clearly defined accountabilities to manage the processes.

Need to maintain collegial culture: while calling for a more structured performance management system, the need to maintain the collegial culture was also underlined in the suggestions made by the participants. The suggestions included: the need to focus on teamwork, involvement in decision making, the use of intrinsic rewards to minimize a divisive effect; equitable allocation of work, recognition of all facets of academic work and the transparency of the system. All these suggested changes are in line with the concept of the collegia; model (Middlehurst 2004), signaling that academics still uphold the value of academic identity and o not want to see it fade away.

Need for effective leaders: To successfully implement an integrated and structured system while maintaining collegiality, at least forty-five participants underscored the importance of effective leadership. As stressed by one senior participant, "The system will become worthless unless we have an effective leader to run it". They characterized an effective leader as someone who has a high degree of motivation to develop people, is effective in communication, and has the ability to create a climate conducive to helping academics achieve their objective. In addition, there was also an expectation that this leadership role should be appointed in a managerial capacity with full commitment to helping academics set targets, maintain the process, provide ongoing support, and follow up. Finding a qualified person to meet these expectations, however, is more than challenging. The expected profile means that the chosen leader should have the necessary academic credentials to act as a „mentor" to provide ongoing support and feedback to academics and the necessary leadership attributes to perform the roles of "facilitator",,communicator" and "manager" to effectively manage the processes.

\section{Conclusion}

The results of this study indicates that administrators believe the purpose of performance management at the State Universities of Cameroon is primarily professional development and that the managerial control aspect is largely neglected. This belief is largely linked to the deeply-held values of participants nurtured by a collegial culture and traditional academic identity.

The discussion of the findings on the effectiveness of the current processes provides evidence that academics find difficulty in setting their priorities due to a multiplicity of demands, lack of clear direction from the authorities, and time constraints. Another concern is about the appropriateness of measures to accurately evaluate their performance. Research on academic motivation confirms that individuals tend to be more responsive to intrinsic rewards than financial incentives, which further undermine the perceived effectiveness of current performance management processes. The study also reveals that the administrators delegate the performance management responsibilities to academic leaders. The lack of vested authority, along with the difficulty in stretching enough time to carry out performance management activities in a truly professional way, adversely impacts their effectiveness in performing the role.

Given that the performance management system has been only loosely implemented, most administrators do not seem to find difficulty in adapting to the system.

\section{References}

Armstrong, M. and A. Baron (2004). Managing performance: Performance management in action. London, Chartered Institute of Personnel and Development.

Barnes, C. (2000). "A working social model? Disability, work and disability politics in the 21st century." Critical Social Policy 20(4): 441-457.

Brown, A. (2005). "Implementing performance management in England"es primary schools." International Journal of Productivity and Performance Management 54(5): 468-481.

International Journal of Educational Studies Vol. 1, No. 2, pp. 132-140

2018

DOI: 10.53935/2641-533x.v1i2.81 Funding: This study received no specific financial support. financial support.

Article History:

Received: 18 June 2018

Revised. 2 October 2018

Accepted: 23 November 2018

Published: 21 December 2018

() 2018 by the authors; licensee Academic

Publishing Group

139
K. (2005). "A meta-analytic review of work-family conflict and its antecedents." Journal of Vocational Behavior 67(2): 169198.

Clark, B. (1983). The higher education system. University of California Press, Berkeley,CA.

Cohen, L., J. Duberley, et al. (1999). "Fuelling discovery or monitoring productivity. Research sciences ${ }^{\text {ee }}$ changing perception of management." Organization 6(3): 473-497.

Dearlove, J. (1998). "The deadly dull issue of university administration, good governance, managerialism and organising academic work." Higher Education Policy 11(1): 59-80.

Deem, R. (1998). "New managerialisme and higher education. The management of performance and cultures in universities in the United Kingdom." International Studies in Sociology of Education 8(1): 47-69. 
Deem, R. (2001). "Globalization, New managerialism, academic capitalism and entrepreneurialism in universities; is the local dimension still important?" Comparative Education 37(1): 7-20.

Deem, R. (2004). "The knowledge worker, the manager-academic and the contemporary UK university: New and old forms of public management?" Financial Accountability and Management 20(2): 107-128

Deem, R. and K. Brehony (2005). "Management as ideology: The case of „new managerialism in higher education." Oxford Review of Education 31(2): 217-235.

Den Hartog, D., J. Boselie, et al. (2004). "Performance management: A model and research Agenda." Applied Psychology An International Review 53(4): 556-569.

Elton, L. (2004). "Good hart"s law and performance indicators in higher education." Evaluation and Research in Education 18(1-2): 120-128.

Ferlie, E., L. Ashburner, et al. (1996). The new public management in action. Oxford, Oxford University Press.

Grant, H. (1998). "Academic contests? Merit pay in Canadian Universities." Industrial Relations 53(4): 1-21.

Harley, S. and F. Lee (1997). "Research selectivity, managerialism and the academic labour process: The future of nonmainstream economics in UK Universities." Human Relations 50(11): 1427-1460.

Henkel, M. (1997). "Academic values and the university as corporate enterprise." Higher Education Quarterly 51(2): 134-143.

Jackson, M. (2001). "Personnel management in UK universities." Personnel Review 30(4): 404-420.

Jarratt, A. (1985). Report of the steering committee for efficiency studies in universities. London, UK, Committee of ViceChancellors and Principals.

Jary, D. and M. Parker (1998). The new higher education. UK, Stoke on trent. Staffordshire University Press.

Kohn, A. (1993). "Why incentive plans cannot work." Harvard Business Review 71(16): 54-63.

Lacy, F. and B. Sheehan (1997). "Job satisfaction among academic staff: An international perspective." Higher Education 34: $305-322$.

McNay, I. (1999). The paradox of research assessment and funding in henkel, m. And little, b. (eds), changing relationships between higher education and the state. London, UK, Jessica Kingsley Publishers.

Middlehurst, R. (2004). "Changing internal governance: A discussion of leadership roles and management structures in Uk universities." Higher Education Quarterly 58(4): 258-279.

Middlehurst, R. and T. Kennie (2003). Management for performance today and tomorrow in hall, a. (ed.), managing people managing universities \& colleges: Guides to good practice. Bershire, UK, Open University Press.

Pollitt, C. (1993). Management and the public services. Oxford, UK, Basil Blackwell.

Prewitt, L., D. Phillips, et al. (1991). "Merit pay in academia: Perceptions from the school of business." Public Personnel Management 20(4): 409-417.

Prichard, C. and W. Hugh (1997). "Just how managed is the McUniversity?" Organization Studies 18(2): 287-316.

Randle, K. and N. Brady (1997). "Managerialism and professionalism in the „cinderella service." Journal of Vocational Education and Training 49(1): 121-139.

Simmons, J. (2002). "An Expert witness perspective on performance appraisal in universities and colleges." Employee Relations 24(1): 86-100.

Slaughter, S. and L. Leslie (1997). Academic capitalism -politics, policies and the entrepreneurial university. Baltimore, MD, The Johns Hopkins University Press.

Stiles, P., L. Gratton, et al. (1997). "Performance management and the psychological contract." Human Resource Management Journal 7(1): 57-66.

Talib, A. (2003). "The offspring of new public management in english universities." Public Management Review 5(4): $574-583$.

Varlaam, A., D. Nuttal, et al. (1992). What makes teacher tick? A survey of teacher morale and motivation. Centre for Educational Research, LSE, Clare Market Papers No. 4.

Williams, R. (2002). Managing employee performance: Design and implementation in organizations. London, UK, Thompson Learning.

Wilson, T. (1991). "The proletarianisation of academic labour." Industrial Relations Journal 22(4): 250-262. 